\title{
VISUAL OUTCOME AND COMPLICATIONS OF PEDIATRIC CATARACT SURGERY AT LUMBINI EYE INSTITUTE, NEPAL
}

\author{
Hari B. Thapa ${ }^{1}$, Salma KC Rai ${ }^{2}$, Arjun Malla Bhari ${ }^{2}$, Ken Bassett ${ }^{3}$
}

\begin{abstract}
INTRODUCTION: Pediatric eye care, including cataract surgery, has become much more common in Nepal in recent years in tertiary facilities such as the Lumbini Eye Institute (LEI). This study provides the first report of visual outcome and complications after cataract surgery at that Institute.
\end{abstract}

MATERIAL AND METHODS: This is a prospective observational study of all cataract surgical patients $<16$ years of age between March 1, 2011, and February 28, 2012. Visual outcome was assessed by two optometrists with pediatric eye care training. Clinical data were gathered in a specifically designed pediatric eye program database and demographic data were taken from hospital administrative records.

RESULTS: In 2011-12, 334 children (248 boys [74\%]) underwent cataract surgery, including 89 Nepali (27\%) and 245 Indian (73\%) children. In total, $320(96 \%), 270$ (81\%), and 190 (57\%) attended their first, second and third follow up visits respectively. Pre-operative visual acuity was $<6 / 60(91 \%), 6 / 60$ to $<6 / 18(7 \%)$ and $>6 / 18(2 \%)$. Post-operatively, visual acuity was $<6 / 60(27.5 \%), 6 / 60$ to $<6 / 18(36.5 \%)$ and $6 / 18$ or better $(36 \%)$. The mean best corrected visual acuity was $6 / 38$ first follow up, $6 / 34$ second follow up, and $6 / 30$ third follow up. Intraoperative complications were $1.6 \%$ pupillary capture and post-operative complications were $35.3 \%$ posterior capsular opacification (PCO).

CONCLUSION: For $63 \%$ of children, visual acuity significantly improved with cataract surgery beyond their presenting vision of $<6 / 60$, with over $38 \%$ of children achieving visual acuity $(>6 / 18)$. Follow up beyond one month needs significant improvement to treat postoperative complications particularly posterior capsular opacification.

KEYWORDS: Cataract surgery; Pediatrics; Visual outcome

1. Optometrist, Lumbini Eye Institute, Bhairahawa, Nepal

2. Pediatric Ophthalmologist, Lumbini Eye Institute, Bhairahawa, Nepal

3. Seva Foundation, Canada

\author{
For correspondence \\ Hari Bhadur Thapa, M Optom, MA, \\ Low Vision Clinic, \\ Lumbini Eye Institute, Bhairahawa, Nepal \\ E-mail: haribdr2005@yahoo.com
}




\section{BACKGROUND}

Lumbini Eye Institute (LEI) in Bhairahawa, Nepal, has become the tertiary pediatric referral center for western Nepal and the northern Indian state of Uttar Pradesh (and to a lesser extent Bihar) with a pediatric ward and dedicated operating rooms as well as ophthalmologists, nurses, and ophthalmic assistants specializing in pediatric care. Its program, similar to other pediatric programs in $\mathrm{Nepal}^{1}$ and other low-income countries ${ }^{2,34}$ needs systematic and ongoing evaluation of the visual and functional outcome of the surgical program.

A study in 2011-12, evaluating a new pediatric cataract surgical follow-up program at LEI, reported a significant increase in the proportion of children attending their first, second, and third follow-up visits compared to 2009-10. ${ }^{5}$ However, they did not report details of visual outcome or complications.

\section{MATERIAL AND METHODS}

All children $<16$ years of age at LEI from March 1, 2011, to February 28, 2012, who had surgery for congenital, developmental, or traumatic cataract were included. Children receiving a second cataract surgical operation were excluded. Data were prospectively collected in a newly developed pediatric database for all eligible children. Data were gathered on standardized preoperative, intra-operative, and postoperative forms and included social and demographic information on parents' education and occupation and place of residence. Both the pediatric counselor and the program director were responsible for data collection.

First follow-up was defined as any visit up to 3 weeks after surgery. The second follow-up (only for children attending first follow-up) was up to 12 weeks, and the third follow-up (only for attainders of the first 2 visits) was up to 24 weeks. The research adhered to the guidelines of the declaration of Helsinki. Ethical approval was obtained from the Ethics Committee of Lumbini Eye Institute that includes a research monitoring function.

\section{RESULTS}

In 2011-12, 334 children (248 males [74\%]), including 89 Nepali (27\%) and 245 Indian (73\%) underwent cataract surgery (Table 1). These included traumatic 152(45\%), congenital $126(38 \%)$ and developmental 56(17\%) cases.
Table1: Cataract surgical cases by age and sex

\begin{tabular}{|l|c|c|l|}
\hline & Boys & Girls & Total $(\mathbf{\%})$ \\
\hline$>2 \leq 6$ years & 26 & 10 & $36(11)$ \\
\hline$>6 \leq 15$ years & 55 & 27 & $82(25)$ \\
\hline Total & 167 & 49 & $216(64)$ \\
\hline
\end{tabular}

Table 2: Pre and post operative visual acuity by age group

\begin{tabular}{|c|c|c|c|c|c|c|c|c|}
\hline \multirow[t]{2}{*}{ Age range } & \multicolumn{3}{|c|}{ Pre operative visual acuity } & & \multicolumn{3}{|c|}{$\begin{array}{l}\text { Post operative visual acuity at different } \\
\text { visits }\end{array}$} & \multirow[b]{2}{*}{ Total } \\
\hline & $\begin{array}{l}6 / 6-6 / 18 \\
\mathrm{~N}(\%)\end{array}$ & \begin{tabular}{|l}
$<6 / 18-$ \\
$6 / 60$ \\
$\mathrm{~N}(\%)$
\end{tabular} & $\begin{array}{l}<6 / 60 \\
\mathrm{~N}(\%)\end{array}$ & & $\begin{array}{l}6 / 6-6 / 18 \\
\mathrm{~N}(\%)\end{array}$ & $\begin{array}{l}<6 / 18-6 / 60 \\
\mathrm{~N}(\%)\end{array}$ & $\begin{array}{l}<6 / 60 \\
\mathrm{~N}(\%)\end{array}$ & \\
\hline $0-2$ yrs & 0 & 0 & $36(100)$ & 36 & 0 & $31(86)$ & $5(14)$ & 36 \\
\hline$>2-6$ yrs & $2(2)$ & $4(5)$ & $80(93)$ & 86 & $18(21)$ & $40(47)$ & $28(32)$ & 86 \\
\hline$>6-15 \mathrm{yrs}$ & $5(2)$ & $21(10)$ & $186(88)$ & 212 & $102(48)$ & $51(24)$ & $59(28)$ & 212 \\
\hline Total & $7(2$ & $25(7)$ & $302(91)$ & & $120(36)$ & $122(36.5)$ & $92(27.5)$ & $334(100)$ \\
\hline
\end{tabular}

Pre-operative visual acuity was $<6 / 60$ (91\%), 6/60 to $<6 / 18(7 \%)$ and $6 / 18$ or better $(2 \%)$. Postoperatively, visual acuity was $<6 / 60(27.5 \%), 6 / 60$ to $<6 / 18(36.5 \%)$ and $6 / 18$ or better (36\%). (Table 2 ) The mean final post operative BCVA in unilateral cases was $6 / 40$ unit and it was $6 / 38$ unit for the bilateral cases.

Table 3: Post operative BCVA at $1^{\text {st }}, 2^{\text {nd }}$ and $3^{\text {rd }}$ follow up

\begin{tabular}{|l|r|r|r|r|}
\hline \multicolumn{7}{|l|}{$\begin{array}{l}\text { Pre operative } \\
\text { Visual Acuity }\end{array}$} & \multicolumn{2}{l|}{$\begin{array}{l}\text { 1st follow up visit } \\
\text { Visual acuity N }(\%)\end{array}$} & $\begin{array}{l}\text { 2nd follow up visit } \\
\mathrm{N}(\%)\end{array}$ & $\begin{array}{l}\text { 3rd follow up } \\
\text { visit N (\%) }\end{array}$ \\
\hline $6 / 6-6 / 18$ & $7(2)$ & $118(36.9)$ & $102(37.8)$ & $73(38.5)$ \\
\hline$<6 / 18-6 / 60$ & $25(7)$ & $117(36.6)$ & $95(35.2)$ & $74(38.9)$ \\
\hline$<6 / 60$ & $302(91)$ & $85(26.5)$ & $73(27.0)$ & $43(22.6)$ \\
\hline Sub-total & $334(100)$ & $320(96)$ & $270(81)$ & $190(57)$ \\
\hline
\end{tabular}

The proportion of children with different levels of best corrected visual acuity were similar for all three postoperative visits: first follow up was in $<6 / 60$ (26.5\%), 6/60 to $<6 / 18(36.6 \%)$ and $>6 / 18(36.9 \%)$; second follow up $<6 / 60$ (27\%), $6 / 60$ to $<6 / 18(35.2 \%)$ and $>6 / 18(37.8 \%)$ and third follow up $<6 / 60(22.6 \%), 6 / 60$ to $<6 / 18-6 / 60$ (38.9\%) and $>6 / 18(38.5 \%)$ (Table 3$)$. 


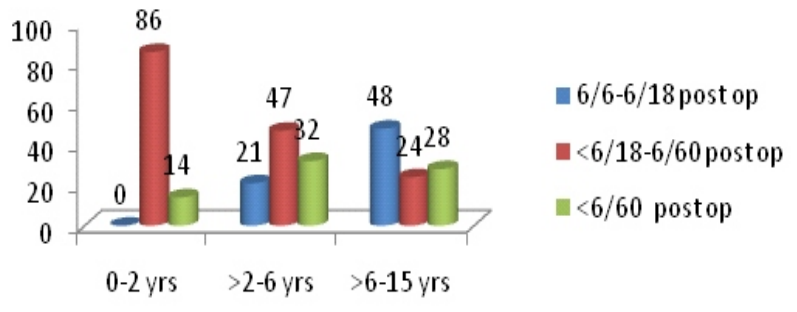

age groups

The proportion of children with post operative visual acuity $>6 / 18$ increased with increasing age, with the highest (48\%) age $>6$ yrs (Figure 1). The proportion of children who had post-operative visual acuity $>6 / 18$ differed depending on the causes of cataract with $52 \%, 40 \%$, and $24 \%$ for developmental, traumatic and congenital cataract, respectively (Table 4).

\section{Table 4: Post operative BCVA at different types of} cataract

\begin{tabular}{|l|c|c|c|c|}
\hline \multirow{2}{*}{$\begin{array}{l}\text { Types of } \\
\text { Cataract }\end{array}$} & \multicolumn{3}{|l|}{ BCVA at different f/u } & Total \\
\cline { 2 - 5 } & $\begin{array}{c}6 / 6-6 / 18 \\
\mathrm{~N}(\%)\end{array}$ & $\begin{array}{c}<6 / 18-6 / 60 \\
\mathrm{~N}(\%)\end{array}$ & $\begin{array}{c}<6 / 60 \\
\mathrm{~N}(\%)\end{array}$ & $\mathrm{N}(100)$ \\
\hline Congenital & $30(24)$ & $60(48)$ & $36(28)$ & $126(100)$ \\
\hline Developmental & $29(52)$ & $14(25)$ & $13(23)$ & $56(100)$ \\
\hline Traumatic & $61(40)$ & $48(32)$ & $43(28)$ & $152(100)$ \\
\hline Total & 120 & 122 & 92 & 334 \\
\hline
\end{tabular}

It was found that $35.3 \%$ children had posterior capsular opacification (PCO) and 1.6\% had pupillary capture in post operative complication. There were $13 \%$ children with nystagmus.

\section{DISCUSSION}

Blindness in children remains the second leading cause of "blind-person years" worldwide". Historically, the leading cause of blindness among Nepali children was corneal scarring secondary to measles and vitamin A deficiency. ${ }^{6}$ However, these blinding corneal diseases have been significantly reduced in recent years by better primary health care and the success of international health promotion efforts, such as the WHO/UNICEF Extended Program of Immunization. $^{7-10}$ In contrast, data from hospitals and screening camps suggest that the prevalence of childhood cataract has not decreased in recent years and that it remains a leading causes of blindness in Nepal.

Pediatric cataract, especially congenital cataract, often causes severe visual impairment because of sensory deprivation during the sensitive period of visual development. In our study, only $16 \%$ of congenital cataract $(12 \%$ bilateral and $4 \%$ unilateral) received operations before the age of one year. A more comprehensive community-based program, perhaps tied to maternal-child health activities, near the time of birth is needed in Nepal to identify more of these children at a younger age.

In our series, 152 children (45\%) had traumatic cataract. The high proportion of traumatic cataract is likely because Lumbini Eye Institute provides emergency surgical services for a very large primarily agricultural population where children, who must work in farm labor from a young age, are commonly injured.

The mean post-operative best corrected VA of congenital cataract was $6 / 40$.This result is slightly worse than previous studies that reported the mean best corrected VA of 6/12 in bilateral cases and 6/60 in unilateral cases. This improved VA is likely due to more cases ( $40 \%$ bilateral and $50 \%$ unilateral cases) receiving operations by the age of 3 months. ${ }^{11,12}$ The timing of congenital cataract surgery is the most important factor for visual prognosis, with earlier cataract extraction having a better visual outcome. ${ }^{13}$

In our study, $17 \%$ of pseudophakic eyes had $>6 / 9.5$ compared with only $1 \%$ of aphakic eyes. In a French study, the proportion of pseudophakic eyes with a visual acuity $>6 / 9.5$ was higher $(40 \%)$ compared with the two aphakic eyes which were both $<6 / 19 .{ }^{14}$ Gimbel et al. reported on 24 pseudophakic eyes in children who were operated on over the age of 2 and found that the visual acuity was $>6 / 124$ years after surgery in $79.2 \%$ of cases. ${ }^{15}$ Our surgical approach to cataract extraction and IOLimplantation in younger children included careful management of posterior capsule opacification which occurred in $35 \%$ of children... Trivedi et al. reported a similar proportion of visual axis opacification in $37.9 \%$ of children less than 1 year of age even though a PPC with anterior vitrectomy had been performed ${ }^{16}$.

In our study, $13 \%$ of patients had nystagmus preoperatively. It should be noted that in early bilateral cataracts, the existence of nystagmus plays a determining role in functional visual prognosis. The work of Robb and Petersen ${ }^{17}$ has shown poor visual results in children who had nystagmus before surgery. The nystagmus did not appear to improve after surgery (based on clinical observation), which is in contrast to reports in a study from Africa. ${ }^{3}$ In a previous study done in Nepal, $16 \%$ of the patients had nystagmus preoperatively. ${ }^{1}$ 


\section{CONCLUSION}

For $63 \%$ of children, visual acuity significantly improved with cataract surgery beyond their presenting vision of $<6 / 60$, with over $38 \%$ of children achieving visual acuity $(>6 / 18)$. Follow up beyond one month needs improvement to treat postoperative complications.

\section{ACKNOWLEDGMENTS}

Lions Club International Foundation, Bausch+Lomb Early vision Institute provided support for program activities and Seva Nepal \& Canada provided support for operational activities.

\section{REFERENCES}

1. Thakur J, Reddy H, Wilson E, et al. Pediatric cataract surgery in Nepal. J Cataract RefractiveSurg. 2004; 30: 16291635. available from http://www.cureblindness.org/fileadmin/files $/ P D F s / H C P$ Pediatric_Cataract_Surgery_in_Nepal.pdf http://dx.doi.org/10.1016/j.jcrs.2003.12.047 PMid:15313283

2. Eriksen JR, Bronsard A, Mosha M, et al. Predictors of poor follow-up in children that had cataract surgery. Ophthalmic Epidemiol. 2006; 13: 237243.

http://dx.doi.org/10.1080/09286580600672213

PMid:16877282

3. Yorson D, Wood M, Foster A. Results of cataract surgery in young children in East Africa. Br J Ophthalmol. 2001; $85: 267271$

http://dx.doi.org/10.1136/bjo.85.3.267 PMCid:PMC1723882

4. Bowman RJC, Kabiru J, Negretti G, et al. Outcomes of bilateral cataract surgery in Tanzanian children. Ophthalmol.2007; 114: 22872292.

http://dx.doi.org/10.1016/j.ophtha.2007.01.030

PMid:17448539

5. Rai S,Thapa H, Kandel RP, et al. Clinical and cost impact of a pediatric cataract follow-up program in western Nepal and adjacent northern Indian States. JAAPOS. 2014; 18: 67-70. http://dx.doi.org/10.1016/j.jaapos.2013.09.008 PMid:24568986

6. Brilliant GE. The epidemiology of blindness in Nepal: report of the 1981 Nepal blindness survey. Chelsea, MI: Seva Foundation; 1988. PMid:3175925

7. Pokharel GP, Pant CR, Tilden RL, et al. Nutrition education and mega-dose vitamin A supplementation in Nepal. Indian $J$ Pediatr. 1998; 65: 547555.

http://dx.doi.org/10.1007/BF02730892 PMid:10773903
8. Pant CR, Pokharel GP, Curtale F, et al. Impact of nutrition education and mega-dose vitamin A supplementation on the health of children in Nepal. Bull World Health Organ.1996; 74: 533545 .

PMid:9002334 PMCid:PMC2486860

9. J.L. Fiedler. The Nepal National Vitamin A Program: prototype to emulate or donor enclave? Health Policy Plan.2000; 15:145156 http://dx.doi.org/10.1093/heapol/15.2.145 PMid:10837037

10. A. Foster, D. Yorston . Corneal ulceration in Tanzanian children: relationship between measles and vitamin A deficiency. Trans $R$ Soc Trop Med Hyg. 1992; 86: 454455.

http://dx.doi.org/10.1016/0035-9203(92)90268-H

11. Foster A, Gilbert C, Rahi J. Epidemiology of cataract in childhood: a global perspective.J. Cataract Refract. 1997; 23 (1): 601-4. http://dx.doi.org/10.1016/S0886-3350(97)80040-5

12. Ledoux, D.M., Trivedi, et al. Pediatric cataract extraction with intraocular lens implantation: visual outcome when measured at age four years and older. J. AAPOS. 2007; 11: 18224. http://dx.doi.org/10.1016/j.jaapos.2006.11.003 PMid:17306994

13. Laurence C Lesueur, Jean L Arné, Eric C Chapotot, et al. Visual outcome after pediatrics cataract surgery: is age a major factor? Br JOphthalmol.1998; 82:10221025. http://dx.doi.org/10.1136/bjo.82.9.1022

14. Gimbel HV, Ferensowicz M, Raanan M, et al. Implantation in children. J Pediatr Ophthalmol Strabismus. 1993; 30: 6979. PMid:8501620

15. Trivedi, RH, Wilson Jr, et al. Opacification of the visual axis after cataract surgery and single acrylic intraocular lens implantation in the first year of life. J. AAPOS. 2004;8: 156164. http://dx.doi.org/10.1016/j.jaapos.2003.10.008

16. Sidky, Abdelmoaty, Abdulmutalib H, et al. The outcome of congenital cataract surgery in Kuwait. Saudi Journal of Ophthalmology. 2011; 25:295299.

http://dx.doi.org/10.1016/j.sjopt.2011.01.002 PMid:23960940 PMCid:PMC3729344

17. Robb RM, Petersen RA. Outcome of treatment for bilateral congenital cataracts. Ophthalmic Surg. 1992; 23:6506 PMid:1436963 